\title{
TRADUÇÃO NA UNIVERSIDADE FEDERAL DO PARANÁ
}

\section{TRANSLATION AT THE FEDERAL UNIVERSITY OF PARANÁ, BRAZIL}

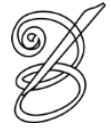 \\ Organizador do número especial: \\ Rodrigo Tadeu GONÇALVES* \\ Universidade Federal do Paraná \\ Curitiba, Paraná, Brasil \\ Apresentação redigida por: \\ Maurício Mendonça CARDOZO** \\ Rodrigo Tadeu GONÇALVES \\ Universidade Federal do Paraná \\ Curitiba, Paraná, Brasil
}

\section{Essa coisa chamada Tradução em Curitiba}

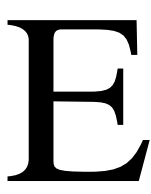

ntender o lugar que a tradução acabaria ocupando em Curitiba, em geral, e na Universidade Federal do Paraná, em particular, é uma tarefa mais complexa do que parece - mesmo para muitos daqueles que contribuíram para a consolidação desse lugar -, e certamente poderia ser melhor investigada em monografias, dissertações e teses dedicadas a esse assunto, do que no que se pode esboçar em algumas poucas páginas. A intuição nos faz crer, no entanto, que talvez se trate menos de uma singularidade do lugar ou das pessoas desse lugar - no sentido de algo que só pudesse ter acontecido ou só aconteça em Curitiba - do que uma singularidade do modo de relação que funda um lugar para a tradução por essas bandas. Assim, estudar o lugar da tradução em Curitiba talvez seja mais revelador da importância e do significado da própria tradução, como prática social, do que das especificidades desse lugar por mais que essas duas coisas caminhem sempre juntas.

Sabemos que o envolvimento com a prática de tradução, no meio universitário, costuma se manifestar, em especial, nos departamentos de letras estrangeiras, embora também se faça presente em outros departamentos. Sabemos que a tradução, como questão de ordem teórica e crítica, sempre encontra grande interesse da parte de alunos e professores, apesar de sabermos também que a tradução convive com certa resistência e desconfiança do restante do meio acadêmico. E sabemos, ainda, que a experiência da tradução costuma implicar o envolvimento 
com várias áreas de especialidade da tradução, mesmo que a distribuição dessas áreas de especialidade se dê de modo diferente em cada lugar.

$\mathrm{Na}$ UFPR, como em qualquer outra parte, o envolvimento dos docentes e discentes com a prática de tradução sempre englobou diversas áreas de especialidade; no entanto, podemos identificar uma centralidade e predominância do trabalho com a tradução de literatura, o que certamente constitui um aspecto decisivo do modo como se construiu a relação com a tradução nessa instituição. Afinal, é sobretudo a relação com a tradução de literatura, que, por essas bandas de cá, fez emergir o envolvimento com a tradução em outros departamentos que não o de letras estrangeiras modernas. E talvez não seja irrelevante constatar que a maioria absoluta dos docentes envolvidos com a tradução, distribuídos nos vários departamentos que atendem as demandas do curso de graduação em Letras, sejam, ao mesmo tempo: pesquisadores da área dos estudos literários e/ou da área dos estudos da tradução, tradutores de literatura e, em muitos casos, também escritores e poetas. Uma das consequências diretas disso ganha visibilidade no modo como a tradução se institucionalizou no Programa de Pós-graduação em Letras da UFPR: como uma linha de pesquisa da área dos Estudos Literários.

Tendo essas considerações em vista, talvez possamos arriscar dizer que foi a predominância de uma relação produtiva com a tradução de literatura, que, nas últimas décadas, fez com que o interesse pela tradução, na UFPR, se sobrepusesse às desconfianças que sempre se armam como forma de resistência à institucionalização dos campos da pesquisa e da formação em tradução.

\section{Institucionalização da tradução na Universidade Federal do Paraná}

Retomando aqui, em síntese, algumas considerações já apresentadas num texto que refletia sobre a primeira década (2001-2011) desse processo de institucionalização (Cardozo 2013), podemos identificar, como seu marco fundador, a criação, no final do ano de 1997, do Núcleo de Tradução (NUT-UFPR), que entraria efetivamente em operação no início do ano de 1998. ${ }^{1}$ A proposta do NUT era a de criar um espaço institucional: primeiro, para as atividades ligadas ao ensino, incentivando uma oferta mais regular e sistemática de disciplinas de tradução; segundo, para as atividades ligadas à pesquisa, promovendo colóquios, jornadas, cursos de formação e, paralelamente, incentivando a capacitação dos docentes na área específica, com vistas a uma futura integração da tradução ao Curso de Graduação e ao Programa de PósGraduação em Letras; e terceiro, para as atividades ligadas à extensão, criando um Escritório Modelo de Tradução - a Agência do NUT -, em que alguns docentes eram responsáveis por 
promover uma espécie de agenciamento e acompanhamento da interação entre tradutores profissionais e estudantes do Curso de Letras interessados em acompanhar de perto a prática de profissionais da tradução. As atividades da Agência, ainda que riquíssimas para todos os envolvidos, demandavam um custo operacional elevadíssimo - em virtude da estrutura administrativa e burocrática da Universidade, bem como das limitações da força de trabalho. Em razão disso, as atividades da Agência foram suspensas em 2005.

Até 2000, a UFPR contava com um Curso de Graduação em Letras, que oferecia, ao estudante, a possibilidade de cursar uma habilitação simples ou dupla em Língua e Literatura Vernácula, Clássica e/ou Estrangeira. Por sua vez, a habilitação simples ou dupla podia ser cursada em uma das duas modalidades diferentes de formação: como Licenciatura ou como Bacharelado. A tradução, até então, tinha seu lugar restrito à oferta bastante eventual e irregular de algumas disciplinas optativas. Em 1998, iniciou-se um novo processo de reformulação curricular. Entre outras questões, a reavaliação do Curso então vigente diagnosticava uma certa indefinição do perfil de formação do Bacharelado - criado na reforma curricular anterior, de 1991 -, que não se definia senão como uma espécie de via de escape para os alunos que não tinham interesse em cursar a Licenciatura.

No final dos anos 1990, também o Programa de Pós-Graduação em Letras da UFPR passou por um processo de reestruturação, que daria origem ao formato (atualmente vigente) de um curso misto, com duas áreas de concentração: em Estudos Linguísticos e em Estudos Literários.

Esses dois esforços de rediscussão curricular, na graduação e na pós-graduação, acabaram se cruzando e o modelo de reorganização da Pós-Graduação acabou servindo de base para se repensar o problema de perfil formativo que o Bacharelado acusava. A solução foi encaminhada nos termos da criação de pequenas "áreas de concentração" no interior do Bacharelado em Letras, áreas que passaram a ser chamadas de ênfases. Num primeiro momento foi proposta a criação de uma ênfase em Estudos Linguísticos e de uma ênfase em Estudos Literários, à semelhança da organização das áreas de concentração no Programa de PósGraduação em Letras da UFPR. Mas a participação de representantes do Núcleo de Tradução nos dois anos do longo processo de rediscussão curricular do Curso de Letras - que só se encerraria em 2001, com a implantação do novo currículo - seria determinante para que, num segundo momento, analogamente às duas ênfases já propostas, fosse criada ainda uma terceira: a ênfase nos Estudos da Tradução. 
Durante esse longo processo de discussão, uma questão em especial permearia parte da discussão da nova lógica das ênfases. Ao contrário da lógica historicamente estabelecida das Licenciaturas - com um perfil de formação declaradamente profissionalizante e uma estrutura institucional fundada na lógica de áreas distribuídas por línguas (alemão, espanhol, francês, grego, inglês, italiano, latim e português, às quais vieram se somar posteriormente o polonês e o japonês) -, as ênfases do Bacharelado em Estudos Linguísticos e em Estudos Literários propunham uma formação dominantemente acadêmica, no sentido de uma formação que tinha em vista a preparação do estudante para a atividade de pesquisador, ao invés de uma profissionalização, no sentido da habilitação do egresso para o exercício de uma atividade profissional específica. Além disso, sem prescindir da habilitação simples ou dupla em língua vernácula, clássica e/ou estrangeira moderna, a nova lógica de organização das ênfases, em virtude do outro tipo de recorte de áreas que estabelecia, impunha-se como uma possibilidade de reorganização dos saberes e competências também no espaço da Graduação, criando tanto a possibilidade quanto a necessidade de transcender os limites das áreas tradicionalmente instituídas - bem como dos departamentos.

Após dois anos de um longo processo de discussão da proposta, o novo currículo foi finalmente implantado em 2001, de modo que, neste ano de 2019, o curso de Bacharelado em Letras, com ênfase nos Estudos da Tradução, completa a sua maioridade.

O projeto pedagógico final, da qual o curso até hoje é tributário, encontrou forma numa proposta que oferece ao estudante, ao longo de todo o seu percurso formativo em Letras, já desde o primeiro ano, um espaço dedicado à sensibilização tanto para a diversidade e para a complexidade da prática de tradução quanto para a percepção dos diferentes lugares sociais, históricos e epistemológicos em que a tradução se manifesta como questão.

Em outras palavras, trata-se de uma proposta formativa que tem em vista fazer com que o estudante conviva com as questões de tradução ao longo de no mínimo quatro anos de sua formação, promovendo o desenvolvimento de um olhar crítico, a partir do qual os estudantes podem começar a refletir tanto sobre diferentes dimensões e aspectos práticos da tradução quanto sobre seu papel e lugar na história da humanidade e no mundo contemporâneo. A proposta formatada, de um Bacharelado acadêmico, com ênfase em Estudos da Tradução, objetiva construir um espaço em que os estudantes possam ter seu primeiro contato com as práticas de tradução, conhecer sua diversidade e problematizar suas complexidades. E, ainda que não se proponha como um Curso de formação profissionalizante de tradutores, não perdemos de vista a possibilidade de concretizar, nesse espaço, uma oportunidade de os 
estudantes entrarem minimamente em contato com as dinâmicas reguladoras da prática de tradução em nossa sociedade, bem como com recursos tecnológicos que se oferecem como instrumentos dessa prática.

A compreensão, enfim, é a de que este modelo de curso, do ponto de vista da formação em tradução, concentra-se numa proposta mais reflexiva e horizontalizada, desenvolvendo mais centralmente a autonomia crítica do estudante e preparando-o, assim, para seguir seus estudos no âmbito de uma pós-graduação stricto sensu. Entendemos, no entanto, que aqueles estudantes que optam por seguir a carreira de tradutor também podem fazer bom proveito dessa autonomia crítica desenvolvida ao longo de tal formação, no sentido de estarem bem preparados para as demandas específicas de uma futura prática profissional da tradução. Tendo em vista que muitos de nossos egressos são, hoje, tradutores freelancers, tradutores editoriais, tradutores juramentados, mestres e doutores em tradução e em outras áreas das Letras, bem como professores universitários em instituições nacionais e estrangeiras, podemos dizer que o destino de nossos egressos é contraprova inequívoca dessa proposta de curso.

\section{O número especial}

O número especial nasce a partir de um convite da professora Germana Henriques Pereira, dos Estudos da Tradução da Universidade de Brasília, editora-chefe da revista Belas Infiéis. Um convite para mostrar um pouco mais do que se faz em tradução na UFPR. Seria uma oportunidade muito boa para mostrar a enorme diversidade do que fazemos, para além dos grandes nomes que têm recebido prêmios nacionais e reconhecimento para além da instituição, como Regina Przybycien e Guilherme Gontijo Flores (que foram entrevistados para o número especial), Maurício Cardozo (que assina a apresentação) e Caetano Galindo (que integra o número especial como tradutor). Pensamos em mostrar que há muito mais trabalho acontecendo, e, finalmente, após muitos convites, submissões, avaliações, negociações de direitos autorais, temos orgulho de apresentar aqui uma mostra panorâmica composta por três artigos, um ensaio, duas entrevistas e trinta e nove traduções literárias, com um escopo cronológico, linguístico e geográfico bastante amplo, que vai do grego ático do século $\mathrm{V}$ à literatura escrita hoje por jovens que nasceram no final do século XX, com autores latinoamericanos, europeus, africanos, asiáticos, num total de nove línguas. Quanto às tradutoras e tradutores, temos estudantes de graduação e pós-graduação, professores e professoras, egressos e egressas, em uma proporção de quase metade de mulheres (que teríamos conseguido, não fossem alguns pedidos de cessão de direitos negados, o que nos impediu de publicar várias 
outras traduções). O resultado é um panorama da diversidade e da relevância da tradução como mecanismo de abertura para o outro, para estabelecer relações, redes e conexões, e mostrar que não estamos sozinhos.

Gostaríamos de agradecer ao enorme empenho dos editores da Revista Belas Infiéis, especialmente à professora Patrícia Rodrigues Costa, e a todos os pareceristas que tornaram este volume possível: Andréia Guerini, Beethoven Alvarez, Brunno V. G. Vieira, Carolina Paganine, Francisco Innocêncio, Guilherme Gontijo Flores, Jaqueline Bohn Donada, Leonardo Antunes, Luci Collin, Marcelo Jacques de Moraes, Marlova Aseff e Werner Heidermann.

\section{REFERÊNCIAS}

CARDOZO, Mauricio Mendonça. A institucionalização da tradução na Universidade Federal do Paraná: 10 anos do Bacharelado acadêmico em Estudos da Tradução. In: Torres, MarieHélène C; Guerini, Andréia; Costa, Walter C.. (Org.). Os estudos da tradução no Brasil nos séculos XX e XXI. Tubarão; Florianópolis: Copiart; PGET/UFSC, 2013, p. 101-120.

\footnotetext{
${ }^{*}$ Rodrigo Tadeu GONÇALVES - Bacharel em Letras - Latim (2004) e em Letras - Português e Inglês (2003) pela Universidade Federal do Paraná. Doutor (2008) e Mestre (2004) em Letras pela mesma instituição. Realizou pesquisa pós-doutorado na Université Paris-Sorbonne/ENS/CNRS - Centre Léon Robin, CNRS, França. Professor associado II na Universidade Federal do Paraná. Pesquisador do CNPq nível 2 (2017-2020; 2020-2023). Diretor da Editora UFPR. Universidade Federal do Paraná, Setor de Ciências Humanas, Departamento de Polonês, Alemão e Letras Clássicas. Curitiba, Paraná, Brasil.

Currículo acadêmico: http://lattes.cnpq.br/0497560630462156

ORCID: https://orcid.org/0000-0002-2472-1430

E-mail: goncalvesrt@gmail.com

** Maurício Mendonça CARDOZO - Licenciado em Letras: Língua e Literatura Alemã (1995) pela Universidade Federal do Paraná. Mestre (1999) e Doutor (2004) em Letras: Língua e Literatura Alemã pela Universidade de São Paulo. Realizou pesquisa de pós-doutorado na Pontifícia Universidade Católica do Rio de Janeiro (2009 - 2010); na Faculdade de Estudos da Tradução da Universidade de Mainz, Alemanha (2013 - 2014); no Programa de Teoria e História Literária \& Programa de Ciência da Literatura da Universidade Estadual de Campinas (2018 - 2019$).$ Professor associado IV da Universidade Federal do Paraná. Pesquisador do CNPq nível 2. Universidade Federal do Paraná, Setor de Ciências Humanas Letras e Artes, Departamento de Letras Estrangeiras Modernas. Curitiba, Paraná, Brasil.

Currículo acadêmico: http://lattes.cnpq.br/6080426102326479

ORCID: https://orcid.org/0000-0001-9270-6892

E-mail: maumeluco@gmail.com

${ }^{1}$ Entre os fundadores do Núcleo de Tradução da UFPR, uma iniciativa originalmente do Departamento de Letras Estrangeiras Modernas, figuravam os seguintes docentes: Terumi Koto Bonnet Villaba (in memoriam), Regina Przybycien, Luci Collin, Eva Dalmolin, Sandra Novaes, Gerson Carvalho, Guido Engel e Mauricio Cardozo.
} 